\title{
CORROSION AND BIODEGRADABILITY EVALUATION OF STRONTIUM SUBSTITUTED HYDROXYAPATITE COATING ON SURFACE TREATED AZ91 Mg ALLOY FOR BIOMEDICAL APPLICATION
}

\author{
N. Murugan, M. Chozhanathmisra, S. Sathishkumar, P. Karthikeyan and R. Rajavel* \\ Department of Chemistry, Periyar University, Salem 636011, Tamilnadu, India.
}

\begin{abstract}
*Corresponding Author Email: drrajavelpu@gmail.com
\section{ABSTRACT}

Magnesium alloy has attracted great attention as an orthopedic biodegradable implant material due to its close mechanical properties to natural bone and perfect biocompatibility. But the corrosion of magnesium alloy (AZ91 Mg alloy) in physiological solution limits their biomedical application. In the present work, surface treatment of AZ91 $\mathrm{Mg}$ alloy was performed in the mixed acid solution and bioactive strontium substituted hydroxyapatite (Sr-HAP) was electrodeposited on the surface treated AZ91 Mg alloy. The Sr-HAP coating was characterized by Fourier transform infrared spectroscopy (FT-IR), X-ray diffraction (XRD), high resolution scanning electron microscopy (HRSEM) and energy dispersive $X$-ray analysis (EDX) and adhesion strength. The corrosion resistance of the electrodeposited SrHAP on the AZ91 Mg alloy in simulated body fluid (SBF) was evaluated using potentiodynamic polarization studies. Hence, the Sr-HAP coated on surface treated AZ91Mg alloy is predicted to be the most suitable coating material for orthopedic implants.
\end{abstract}

\section{KEY WORDS}

AZ91 Mg alloy; surface treatment; corrosion resistance; orthopedic implants.

\section{Introduction}

Magnesium and its alloys have been attracted great attention as orthopaedic implant materials due to its biocompatibility, biodegradability and the mechanical properties that is close to the natural bone and teeth [1]. However, magnesium and its alloys are highly susceptible to corrosion in physiological conditions especially human body fluid or blood plasma solution [2]. Hence, surface treatments are needed to improve the biocorrosion resistance of magnesium and its alloys. Hydroxyapatite, (HAP $\left[\left(\mathrm{Ca}_{10}\left(\mathrm{PO}_{4}\right)_{6}(\mathrm{OH})_{2}\right]\right)$ is the currently used bio-ceramic and biomedical coating material due to its excellent biocompatibility, bioactivity, and structural similarities close to the minerals of tooth and bone minerals [3]. The biological performance of the HAP based bio-ceramic materials might be improved by the addition of bio-active ions which has stimulated a number of studies on ion substituted HAP coating [4]. Among these, the beneficial effect of strontium is known to be one of the most critical cations in bone activity to promote the growth of osteoblasts and prevent bone resorption [5]. In vivo and in vitro studies exhibited the good biocompatibility, osteoconductivity and bone bonding strength of Sr-HAP coating $[6,7]$. Among various techniques [8-11] electrochemical deposition is one of the most promising methods that has unique advantages due to its capability of forming a uniform coating on a porous substrate or one with complex shape controllability to the thickness, its low deposition temperature and low cost of equipment [12]. 
The aim of our work was to electrochemically 2.3Preparation of electrolyte

fabricate porous $\mathrm{Sr}^{2+}$ substituted HAP coating ( $\mathrm{Sr}$ - The electrolyte for the deposition was prepared by HAP) on Mg alloy. Sr-HAP porous microstructure dissolving analytical grade calcium nitrate dihydrate can be favourable for the growth of cells and rapid adhesion, resulting in a critical stronger bond to the parent tissue [13]. But porous coating of Sr-HAP on Mg alloy decreases the corrosion resistance of $\mathrm{Mg}$ alloy [14]. To overcome these problems it is suggested that surface treatments may be use to improve the corrosion resistance and bone bonding ability of $\mathrm{Mg}$ alloy. Many surface modification techniques have been established to improve the corrosion resistance of the implant. But there are no reports on the surface treatment of $\mathrm{Mg}$ alloy by the mixture of acid which has attracted much attention due to its simplicity, cost effectiveness, bone bonding ability and its applicability to implants with complicated shapes. Thus, based on all the above stated issues, the present work is involved in the development of Sr-HAP coating on surface treated Mg alloy. The Sr-HAP coating on surface treated $\mathrm{Mg}$ alloy will serve as a promising candidate with improved bio-corrosion resistance, bioactivity and mechanical property.

\section{Experimental}

\section{1 $\mathrm{Mg}$ alloy surface preparation}

The AZ91 Mg alloy specimens (Elemental composition wt\%: $0.59 \% \mathrm{Zn}, 0.17 \% \mathrm{Mn}, 8.63 \% \mathrm{Al},<0.05 \% \mathrm{Cu},<0.05 \%$ Fe and balance $\mathrm{Mg}$ ) of dimensions $10 \times 10 \times 5 \mathrm{~mm}^{3}$ embedded in epoxy resin leaving areas of $1 \mathrm{~cm}^{2}$ were used as the substrate material. Before the deposition, surface of all the samples was ground from 800 to 1200 silicon carbide papers $(\mathrm{SiC})$ to ensure uniform surface roughness. After polishing the alloy substrates were subsequently cleaned ultrasonically by deionized water and acetone for $15 \mathrm{~min}$ and then used for further experiments.

\subsection{Surface treatment of AZ91 Mg alloy}

The entire sample surface was subjected to surface treatments by complete immersion in volume concentration of $10 \% \mathrm{H}_{2} \mathrm{SO}_{4}, \mathrm{CH}_{3} \mathrm{COOH}$ and $10 \% \mathrm{HNO}_{3}$, at room temperature for $10 \mathrm{~min}$. After that the surface treated samples were washed with acetone and rinsed by deionized water and then specimens were ultrasonically cleaned with acetone and dried in air.

$\left(\mathrm{Ca}\left(\mathrm{NO}_{3}\right)_{2} .2 \mathrm{H}_{2} \mathrm{O}\right)$, strontium nitrate $\left(\mathrm{Sr}\left(\mathrm{NO}_{3}\right)_{2}\right)$ and diammonium hydrogen phosphate $\left(\left(\mathrm{NH}_{4}\right)_{2} \mathrm{HPO}_{4}\right)$. The amount of the reactants was calculated based on the $\mathrm{Ca} / \mathrm{P}$ target molar ratio 1.67 . The $\mathrm{pH}$ was adjusted to 4.5 using dilute $\mathrm{NH}_{4} \mathrm{OH}$ or $\mathrm{HCl}$.

\subsection{Electrochemical deposition of Sr-HAP}

Electrodeposition of Sr-HAP on AZ91 Mg alloy was carried out in a regular three electrode cell arrangement by galvanostatic method using an electrochemical workstation (CHI $760 \mathrm{C} \quad(\mathrm{CH}$ Instruments, USA)) in which the platinum electrode served as the counter electrode, AZ91Mg alloy and saturated calomel electrode (SCE) as the working and reference electrodes, respectively. The electrodeposition of Sr-HAP was carried out in an aqueous solution containing $0.4 \mathrm{M} \mathrm{Ca}\left(\mathrm{NO}_{3}\right)_{2} .2 \mathrm{H}_{2} \mathrm{O}, 0.1$ $\mathrm{M} \mathrm{Sr}\left(\mathrm{NO}_{3}\right)_{2}$ and $0.3 \mathrm{M}\left(\mathrm{NH}_{4}\right)_{2} \mathrm{HPO}_{4}$ under the magnetic stirring at room temperature $\left(28 \pm 1^{\circ} \mathrm{C}\right)$ and the $\mathrm{pH}$ was maintained at 4.5 at a current densities of $9 \mathrm{~mA} \mathrm{~cm}-2$ for the duration of $30 \mathrm{~min}$. After the deposition, the $\mathrm{Sr}$ HAP coated AZ91 Mg alloy surface was washed with deionized water to remove residual electrolyte, and then naturally dried for $24 \mathrm{~h}$.

\subsection{Mechanical charterzied}

\subsubsection{Adhesion strength}

The adhesion strength of the Sr-HAP, on the bare and surface treated AZ91 Mg alloy samples were studied by pull-out test according to the American Society for Testing Materials (ASTM) international standard F1044 were subjected each sample at least five measurements quick set epoxy adhesive. After heating in an oven at $100{ }^{\circ} \mathrm{C}$ for $60 \mathrm{~min}$ the fixtures were subjected to pull-out test. The cross-head speed of 1 $\mathrm{mm} / \mathrm{min}$, using a universal testing machine (Model 5569, Instron).

\subsection{Surface Characterization of the coatings}

The functional groups of the coatings was characterized by Fourier transform infrared spectroscopy (Impact 400D Nicholet Spectrometer), in the over frequency range from 4000 to $400 \mathrm{~cm}-1$. The surface morphology and micro structure of the coating was observed using high resolution scanning electron microscopy (JEOL JSM-6400, Japan). The phase compositions of the coatings were identified by X-ray diffraction(XRD) (burukan \& advance diffractometter). The scanning angle is ranged from $20^{\circ}$ to $60^{\circ}$ with a scan 
rate of $0.02^{\circ}$. The chemical composition of the samples were investigated by energy dispersive X-ray spectroscopy (EDS).

\subsection{Electrochemical investigation of the coatings}

The corrosion resistance of the uncoated, and Sr-HAP, coated on untreated and surface treated Mg alloy in stimulated body fluid solution (SBF).was evaluated from Potentiodynamic polarization and electrochemical impedance spectroscopy (EIS).The electrochemical measurements were carried out using three electrode cell arrangement using $(\mathrm{CHI} 760$ electrochemical workstation (USA).The saturated calomel electrode served as the reference electrode, The working and counter electrodes were AZ91 Mg alloy and platinum, respectively. The potentiodynamic polarization studies were recorded with a sweep rate of $1 \mathrm{mV}$ the electrochemical impedance studies were recorded with a frequency range $10 \mathrm{~Hz}-100 \mathrm{kHz}$.

\section{Results and discussion}

3.1 Surface characterization of the surface treated SrHAP coating

\subsubsection{FT-IR analysis}

Fig 1. Shows the FT-IR spectra of the Sr-HAP coating on acid treated AZ91 Mg alloy. The characterized peaks appeared at $3589 \mathrm{~cm}-1$ and $1639 \mathrm{~cm}-1$ are attributed to the stretching and bending mode of water molecule. The peaks corresponding to phosphate group of Sr-HAP acid treated at $1017 \mathrm{~cm}$ 1 (v3) and $590 \mathrm{~cm}-1 \& 559 \mathrm{~cm}-1$ (v4) as well as the peaks observed at $1080 \mathrm{~cm}-1$ (v3) and $945 \mathrm{~cm}-1$ (v1. While the, absorption bands at $3448 \mathrm{~cm}-1$ and 636 $\mathrm{cm}-1$ are assigned to the stretching and bending vibration of $\mathrm{OH}^{-}$groups of Sr-HAP. All these peaks confirm the formation of Sr-HAP coating on acid treated AZ91 Mg alloy.

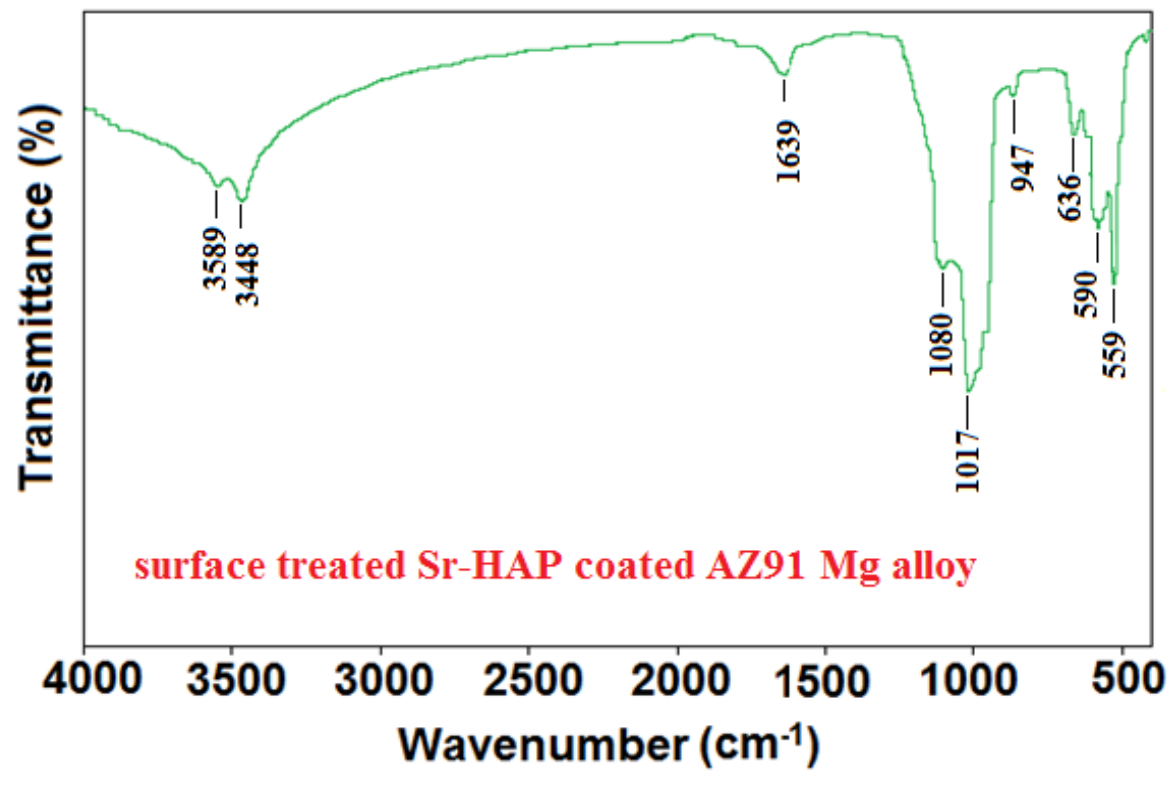

Fig: 1 The FT-IR spectra of surface treated Sr-HAP coated AZ91 Mg alloy

\subsubsection{XRD analysis}

Fig. 2 shows the XRD patterns of the coating on Sr-HAP coating on acid treated AZ91 Mg alloy. The main diffraction peaks of $2 \theta$ values of $25.8^{\circ}, 31.7^{\circ}, 32.4^{\circ}$ and $32.6^{\circ}$ was supports for the formation of Sr-HAP on acid treated $\mathrm{Mg}$ alloy. The characterized peak positions shifted towards the lower $2 \theta$ values from the standard
XRD patterns for HAP, indicating the substitution of $\mathrm{Sr}$ into the HAP lattices as reported by Gopi et.al.61 All these peaks confirm the present of HAP which are well evident from the ICDD card No: 09-0432 these results is good agreement for Sr-HAP coating on AZ91 Mg alloy. 


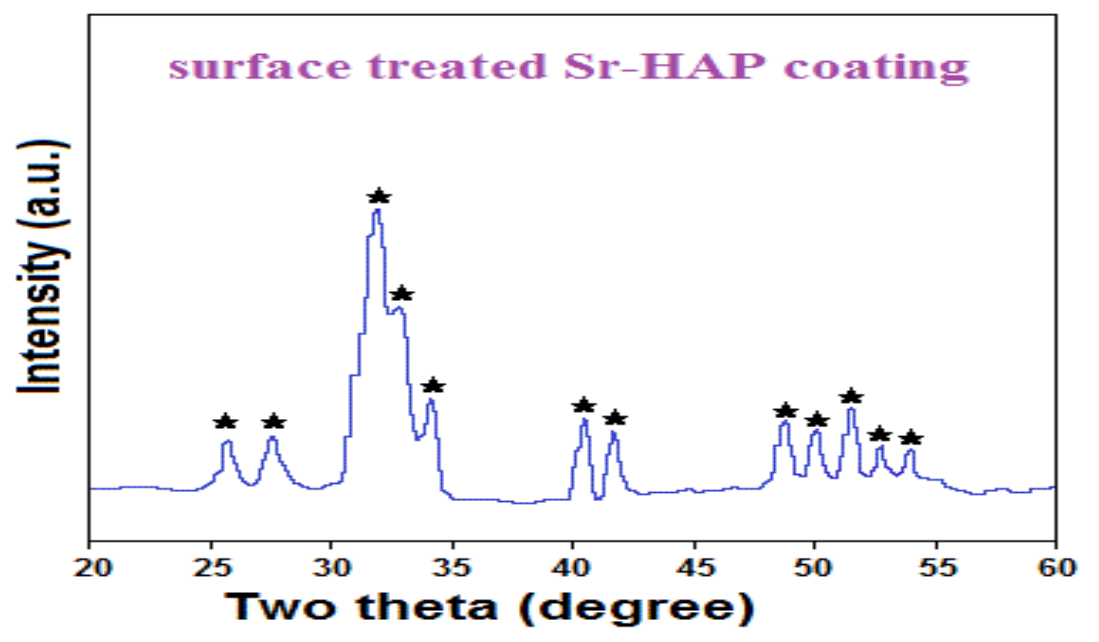

Fig: 2 The XRD pattern of surface treated Sr-HAP coated AZ91 Mg alloy

\subsubsection{SEM and EDS analysis}

Fig. 3(a-c) shows the HRSEM microstructure information of the Sr-HAP coating on untreated AZ91 Mg alloy\& acid treated AZ91 Mg alloy. The surface morphology of Sr-HAP, coating on $\mathrm{mg}$ alloy at current densities of $6 \mathrm{~mA} \mathrm{~cm}-2$ for the duration of $30 \mathrm{~min}$. Fig. 3(b) shows the porous and uniform microstructure structure on surface treated $\mathrm{mg}$ alloy sample surface.

Fig. 3(d) shows the EDS spectrum results indicates the presence of $\mathrm{Ca}, \mathrm{Sr}, \mathrm{O}$ and $\mathrm{P}$ element in the Sr-HAP, coating on the surface of AZ91 Mg alloy.
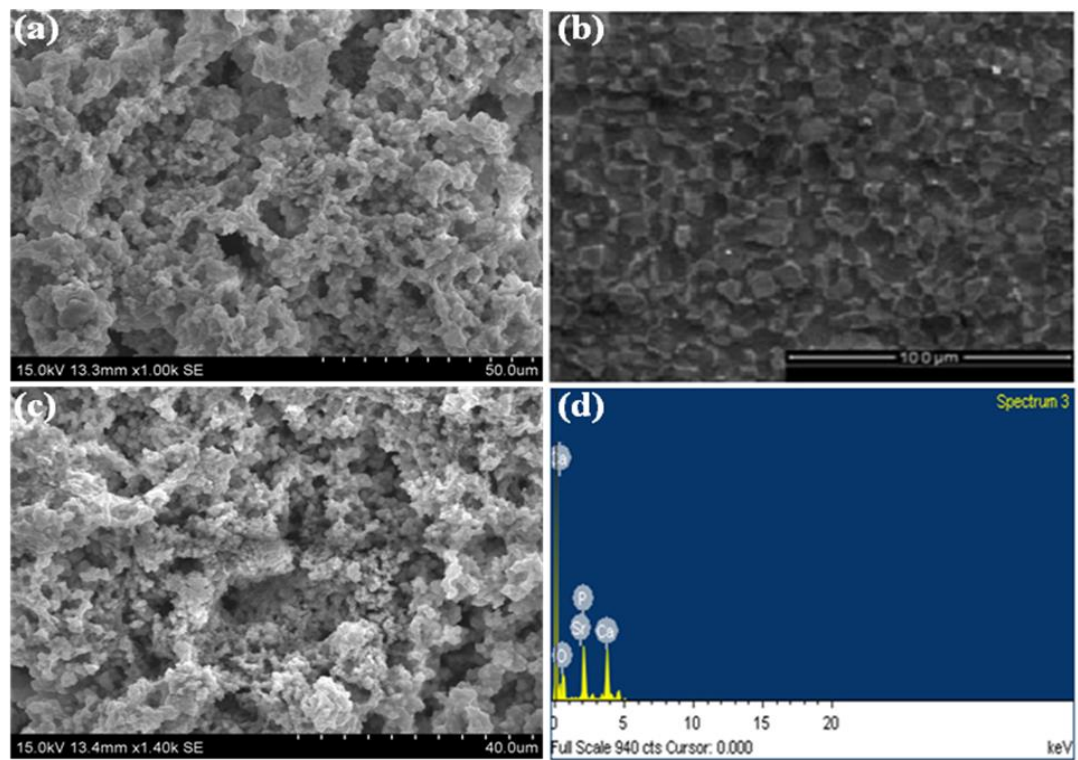

Fig: 3 HRSEM images of (a) Sr-HAP coated (b) surface treated (c) surface treated Sr-HAP coating on AZ91 Mg alloy (d) EDAX spectrum of surface treated Sr-HAP coating on AZ91 Mg alloy

\subsection{Mechanical properties of surface treated Sr-HAP} coating

\subsubsection{Adhesion tests}

The adhesion strength of the Sr-HAP coating on untreated and surface treated AZ91 Mg alloy samples were studied by pull-out test. The adhesion strength of Sr-HAP coating on surface treated $\mathrm{Mg}$ alloy was found higher $(11.3 \pm 0.3)$ then the Sr-HAP coating that was obtained on untreated $\mathrm{Mg}$ alloy $(9.1 \pm 0.2)$ this shows that surface treated $\mathrm{Mg}$ alloy helps in improve the adhesion strength of Sr-HAP coating to the implant. 


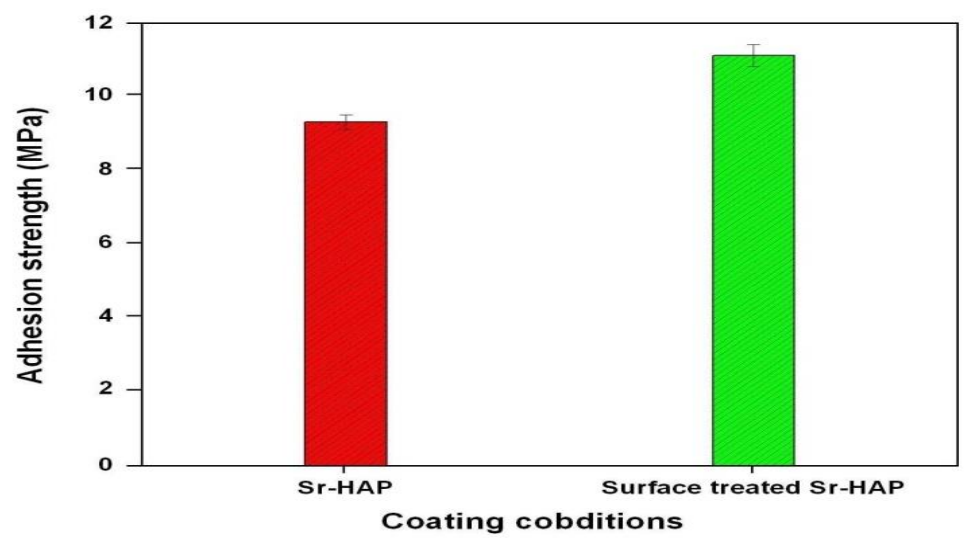

Fig. 4. (a) Adhesion strength of Sr-HAP, surface treated Sr-HAP coated AZ91 Mg Alloy Specimens.

\subsection{Electrochemical characterization}

Corrosion is one of the most important problems for orthopedic applications. corrosion resistance of AZ91
Mg alloy Sr-HAP coated surface treated and untreated, were investigated in SBF solution.

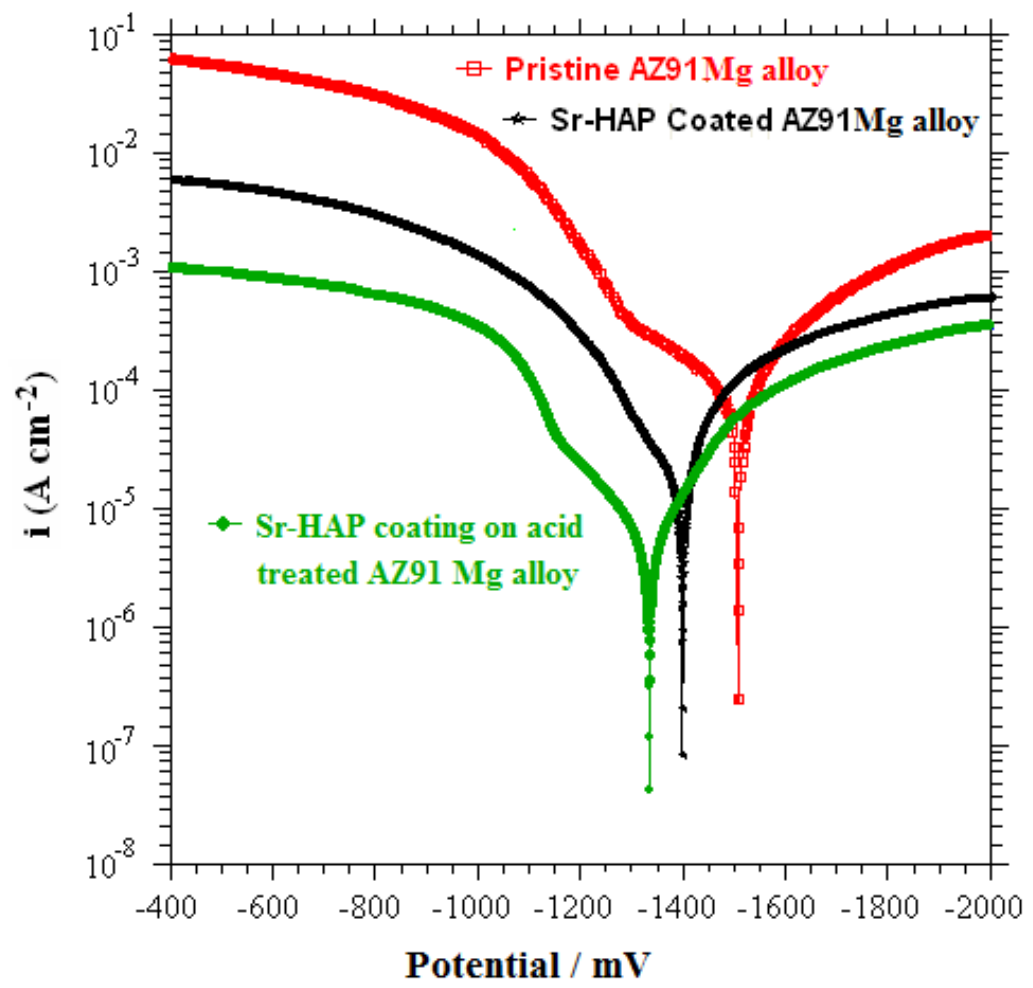

Fig.4. Potentiodynamic polarization curves for uncoated, Sr-HAP, and surface treated Sr-HAP coated AZ91 Mg alloy specimens in SBF solution.

The corrosion potential ( $\left.E_{\text {corr }}\right)$ and corrosion current density (icorr) were calculated from the curves shown in Fig. 4. Uncoated mg alloy specimen was found to be (1510\&9.1) and, Sr-HAP coating on untreated and treated $\mathrm{mg}$ alloy found to be (1390\&2.6and 1335\&1.4). (Ecorr) generally shifted to the positive potential side. It was found that the polarization curves for Sr-HAP coated Mg alloy samples showed much positive shift compare to bare Mg alloy. Similarly Sr-HAP coated on surface treated $\mathrm{Mg}$ alloy exhibited highly corrosion resistance compare to bare $\mathrm{Mg}$ alloy, Sr-HAP coated Mg alloy samples. Generally the positive side shift of corrosion potentials accompanied by decrease of corrosion current indicates that the tendency to corrosion of coated samples decreases. These Sr-HAP coated on surface treated $\mathrm{Mg}$ alloy proved to be better corrosion resistance implant. 


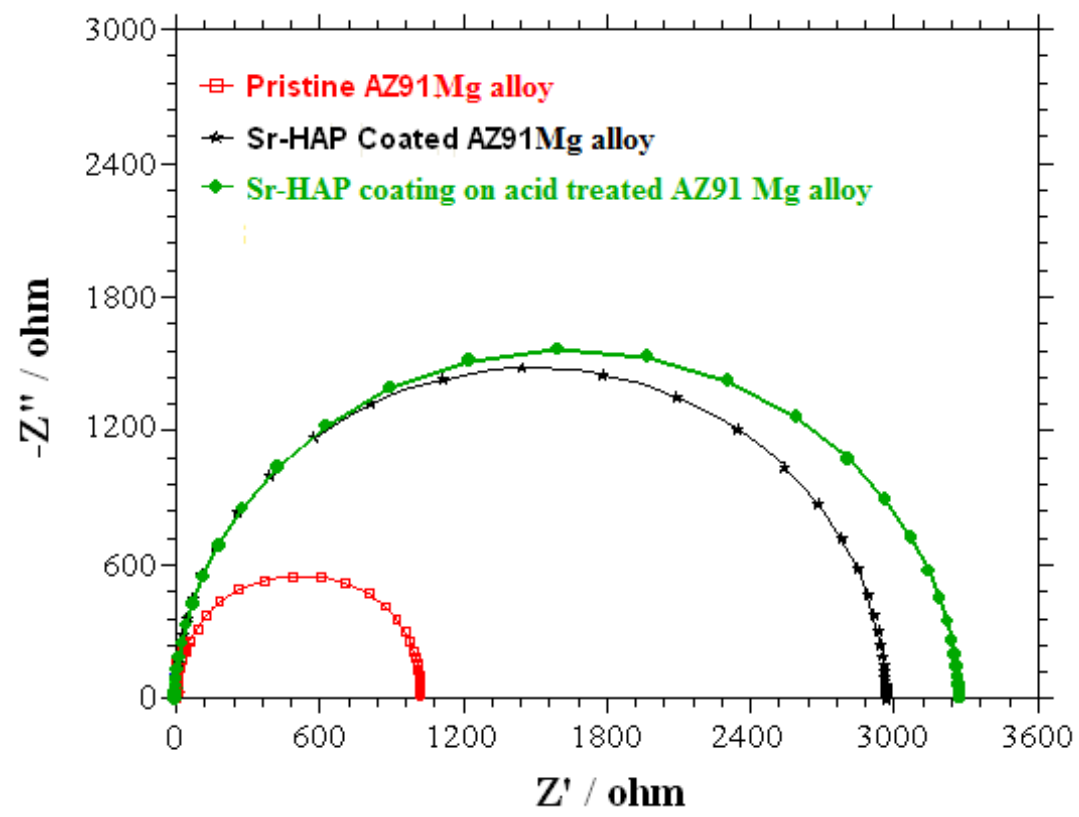

Fig. 5. Nyquist plots for uncoated, Sr-HAP, and surface treated Sr-HAP coated AZ91 Mg alloy specimens in SBF solution.

Fig. 5 showes the Nyquist plots obtained for uncoated Sr-HAP coated, Sr-HAP surface treated coated, were performed in SBF solution were fitted Using equivalent circuits. For the uncoated $\mathrm{Mg}$ alloy samples polarization resistance (Rp) values were 1020 and SrHAP coated samples these values were found to be 2976. respectively for the Sr-HAP coating on surface treated AZ91 Mg alloy were found to be 3468 which is higher than that of the uncoated, Sr-HAP and Sr-HAP surface treated coating on AZ91 Mg alloy is highly corrosion resistance on $\mathrm{Mg}$ alloy surface.

\section{CONCLUSION:}

In this study, electrochemical deposition was successfully coating on surface treated $\mathrm{Mg}$ alloy for improved corrosion resistance and bioactivity. The surface treated Sr-HAP coating exhibited higher corrosion resistance in SBF solution then pure Sr-HAP coating. Furthermore adhesion strength is improved. These results is demonstrated electrodeposition on surface treated Sr-HAP coatings on Mg alloy for use as bioactive coating materials.

\section{REFERENCES}

1. M.P. Staiger, A.M. Pietaka, J. Huadmaia, G. Dias, Magnesium and its alloys as orthopedic biomaterials: a review, Biomaterials 27 (2006) 1728.

2. H.X. Wang, S.K. Guan X. Wanga, C.X. Ren, L.G. Wanga In vitro degradation and mechanical integrity of $\mathrm{Mg}-$
Zn-Ca alloy coated with Ca-deficient hydroxyapatite by the pulse electrodeposition process Acta Biomaterialia 6 (2010) 1743-1748

3. Denissen HW, de Groot K, Makkes PCh, van den Hoff A, Klopper PJ. Tissue response to dense apatite implants in rats. J Biomed Mater Res 1980; 14:713-21.

4. D. Gopi S. Ramya , D. Rajeswari , L. Kavitha Corrosion protection performance of porous strontium hydroxyapatite coating on polypyrrole coated $316 \mathrm{~L}$ stainless steel Colloids and Surfaces B: Biointerfaces 107 (2013) 130- 136

5. Yunfeng Li , Qing Li , songsong Zhu, En Luo, Jihua Li, Ge feng, Yunmao Liao, Jing Hu.The effect of strontiumsubstituted hydroxyapatite coating on implent fixation in ovariectomized rats Biomaterials (Impact Factor: 7.6). 12/2010; 31(34):9006-14.

6. Wong CT, Lu WW, Chan WK, Cheung KM, Luk KD, Lu DS, et al. In vivo cancellous bone remodeling on a strontiumcontaining hydroxyapatite ( $\mathrm{Sr}-\mathrm{HA})$ bioactive cement. J Biomed Mater Res A 2004; 68:513-21.

7. Ni GX, Chiu KY, Lu WW, Wang Y, Zhang YG, Hao LB, et al. Strontium-containing hydroxyapatite bioactive bone cement in revision hip arthroplasty. Biomaterials 2006; 27: 4348-55.

8. I. Pereiro, C. Rodriguez-Valencia, C. Serra, E.L. Solla, J. Serra and P. Gonzalez, Pulsed laser deposition of strontiumsubstituted hydroxyapatite coatings Appl. Surf. Sci., 2012, 258, 9192-9197.

9. A.L. Oliveira, R.L. Reis and P. Li, J. Biomed. Mater. Res. B. Appl. Biomater., Strontium-substituted apatite coating grown on Ti6Al4V substrate through biomimetic synthesis $2007,83,258-265$. 
10. P. Ducheyne, S. Radin, M. Heughebaert and J.C. Heughebaert, Calcium phosphate ceramic coatings on porous titanium: effect of structure and composition on electrophoretic deposition, vacuum sintering and in vitro dissolution Biomaterials, 1990, 11, 244-254.

11. M. Manso, C. Jimenez, C. Morant, P. Herrero and J.M. Martinez-Duart, Electrodeposition of hydroxyapatite coatings in basic conditions Biomaterials, 2000, 21, 17551761.
12. Song YW, Shan DY, Han EH. Electrodeposition of hydroxyapatite coating on AZ91D magnesium alloy for biomaterial application. Mater Lett. 2008; 62: 3276-9.

13. W. Paul and C.P. Sharma, Biomedical Materials and Diagnostic Devices Am. J. Biochem. Biotechnol., 2006, 2, 41-48.

14. X.N.Gu, N.Li, W.R.Zheng, X.Zhao, Q.Z.Cai, Liquan ruan corrosion resistance and surface biocompatibility of a microarc oxidation coating on a Mg-Ca alloy. Acta Biomaterialia 7 (2011) 1880-1889 